\title{
The comparison between prazosin versus clonidine effects on combat related P.T.S.D nightmares
} Seyed Mousavi*1, Majid Barati ${ }^{1}$, Hamid Afshar ${ }^{1}$ and Nasrollah Bashardoust ${ }^{2}$

Address: ${ }^{1}$ Behavioral Sciences Research Center, Isfahan University of Medical Sciences, Iran and ${ }^{2}$ Isfahan University of Medical Sciences, Facutly of Health, Iran

* Corresponding author

\author{
from International Society on Brain and Behaviour: 2nd International Congress on Brain and Behaviour \\ Thessaloniki, Greece. 17-20 November 2005 \\ Published: 28 February 2006 \\ Annals of General Psychiatry 2006, 5(Suppl I):SI 90 doi:I0.1I86/I744-859X-5-SI-SI 90
}

\section{Background}

P.T.S.D is a psychiatric (anxiety) disorder that may develops after a catastrophic stress. One of it's symptoms is nightmares that usually is severe and impaire sleep. Some studies show increased activity of adrenergic system in this disorder.

Also, some drugs such as clonidine, guanfacine and prazosin that decrease the activity of this system, decrease symptoms of PTSD, such as nightmares.

At this study we compared the effects of clonidine versus prazosin on nightmares of these partients.

\section{Materials and methods}

On a dobule blinded clinical trial we studied two groups of inpatient PTSD by using clonidine or prazosin in each group for 8 weeks.

Then we rate the frequency, deepness and serverity of the nightmares by CAPS.

All of the patients were male, married and chronic form of disorder.

The data were analysed by X2, t-pared and t-student.

\section{Results}

In both groups the average of nightmares severity reduced, and they were statistically significant $(\mathrm{p}<0.001)$, but the difference between two groups were not statistically significant $(\mathrm{p}>0.05)$.

\section{Discussion}

Prazosin and clonidine may be effective for treatment of nightmares of PTSD patient's but there are not significant differences between them.

\section{References}

I. Wolf J, Ericson DJ, Sharkansky E, et al.: Course and predictors of posttraumatic stress disorder among gulf war weterans: a prospective analysis. In Yearbook of Psychiatry and Applied Mental Health Edited by: Talbot JA. USA: Mosby; 200I:224.

2. Charong DS, Nagy LM, Daglas J, et al.: Serotonergic system. In Synopsis of Psychiatry Edited by: Fogal B. Williams and Wilkins; 2000:280-283.

3. Jackobs RS, Schnurr PP, Friedman MJ, Pack R, Brophy M, Fuller D: Post traumatic stress disorderand sleep difficulty. Am J Psychiatry 2000, 157:1525.

4. Riynsers RJP, Lamar DM, Diugan HV: Cyproheptadine for PTSD nightmares. Am J 2000, 157:524-525. 